\title{
Ozone Therapy on Rats Submitted to Subtotal Nephrectomy: Role of Antioxidant System
}

\author{
José Luis Calunga, ${ }^{1}$ Zullyt B. Zamora, ${ }^{1}$ Aluet Borrego, ${ }^{1}$ Sarahí del Río, ${ }^{2}$ Ernesto \\ Barber, ${ }^{3}$ Silvia Menéndez, ${ }^{1}$ Frank Hernández, ${ }^{1}$ Teresita Montero, ${ }^{2}$ and Dunia Taboada ${ }^{3}$ \\ ${ }^{1}$ Department of Biomedicine, Ozone Research Center, National Center for Scientific Research, PO Box 6414, Havana, Cuba \\ ${ }^{2}$ Luis Díaz Soto Military Medicine Institute, Havana, Cuba \\ ${ }^{3}$ Victoria de Giron Institute of Basic and Preclinical Sciences, 11600 Havana, Cuba
}

Received 3 March 2005; accepted 13 April 2005

\begin{abstract}
Chronic renal failure (CRF) represents a world health problem. Ozone increases the endogenous antioxidant defense system, preserving the cell redox state. The aim of this study is to evaluate the effect of ozone/oxygen mixture in the renal function, morphology, and biochemical parameters, in an experimental model of CRF (subtotal nephrectomy). Ozone/oxygen mixture was applied daily, by rectal insufflation $(0.5 \mathrm{mg} / \mathrm{kg})$ for 15 sessions after the nephrectomy. Renal function was evaluated, as well as different biochemical parameters, at the beginning and at the end of the study (10 weeks). Renal plasmatic flow (RPF), glomerular filtration rate (GFR), the urine excretion index, and the sodium and potassium excretions (as a measurement of tubular function) in the ozone group were similar to those in Sham group. Nevertheless, nephrectomized rats without ozone (positive control group) showed the lowest RPF, GFR, and urine excretion figures, as well as tubular function. Animals treated with ozone showed systolic arterial pressure (SAP) figures lower than those in the positive control group, but higher values compared to Sham group. Serum creatinine values and protein excretion in 24 hours in the ozone group were decreased compared with nephrectomized rats, but were still higher than normal values. Histological study demonstrated that animals treated with ozone showed less number of lesions in comparison with nephrectomized rats. Thiobarbituric acid reactive substances were significantly increased in nephrectomized and ozone-treated nephrectomized rats in comparison with Sham group. In the positive control group, superoxide dismutase (SOD) and catalase (CAT) showed the lowest figures in comparison with the other groups. However, ozone/oxygen mixture induced a significant stimulation in the enzymatic activity of CAT, SOD, and glutathione peroxidase, as well as reduced glutathione in relation with Sham and positive control groups. In this animal model of CRF, ozone rectal administrations produced a delay in the advance of the disease, protecting the kidneys against vascular, hemorheological, and oxidative mechanisms. This behavior suggests ozone therapy has a protective effect on renal tissue by downregulation of the oxidative stress shown in CRF.
\end{abstract}

\section{INTRODUCTION}

CRF represents a world health problem; once established, it goes irreversibly to a final stage, provoking the patient death. In contrast with the capacity of the kidneys to regain function following acute renal injury, renal injury of a more prolonged nature often leads to progressive and irreversible destruction of nephron mass [1]. Such reduction of renal mass, in turn, causes structural and functional hypertrophy of surviving nephrons. This compensatory hypertrophy is due to an adaptive hyperfiltration mediated by increase in glomerular capillary pressures and flows. Eventually, these adaptations prove maladaptive, predisposing to sclerosis of the residual glomerular

Correspondence and reprint requests to Silvia Menéndez, Department of Biomedicine, Ozone Research Center, National Center for Scientific Research, PO Box 6414, Havana, Cuba; silvia.gra@infomed.sld.cu population $[1,2,3,4]$. The intrarenal vasculature is the most affected structure, preventing an appropriate blood flow, favoring the glomerular sclerosis [1, 2, 3, 4, 5]. For that reason, the improvement of the rheological properties of the blood could delay the progression of the CRF.

Glomerulonephritis was the most common initiating cause of CRF in the past, possibly because of its more aggressive treatment. Now, diabetes mellitus and hypertensive renal diseases are leading causes of CRF. The inexorable course to renal failure often is accompanied by anemia, malnutrition, impaired metabolism of carbohydrates, fats, and proteins, impaired platelet function, and defective utilization of energy [1].

Reactive oxygen species (ROS) play a key intermediary role in the pathophysiologic processes of a wide variety of clinical and experimental renal diseases. It ranges from acute to chronic injuries, making the kidney the site in which several unrelated diseases involve ROS [6]. ROS have been demonstrated to be capable of degrading glomerular basement membrane and inducing 
glomerular injury, characterized by impaired glomerular filtration and sieving function $[7,8]$.

In order to eliminate toxic ROS, cells are equipped with various antioxidant defense systems. Therefore, the development of tissue injury depends on the balance between ROS generation and tissue antioxidant defense mechanism [9]. Among various antioxidant systems equipped within aerobic cells, three antioxidant enzymes, superoxide dismutase (SOD), glutathione peroxidase (GSH-Px), and catalase (CAT), are major mechanisms to reduce local levels of ROS. Thus, these enzymes distributed in cytosol and/or mitochondria can abase primary ROS, such as superoxide anion (by SOD) and hydrogen peroxide (by GSH-Px and CAT) before they can interact to form more reactive cytotoxic metabolites (hydroxyl radical or hypochlorous acid, among others). Studies in the past demonstrated that glomerular antioxidant enzymes levels are modulated. Thus, the glomerular antioxidant enzymes are suggested to play an important role in the functional derangement induced by the ROS [10].

CRF is associated with depressed SOD and elevated NADPH oxidase expression, which can contribute to oxidative stress by increasing superoxide anion [11]. Another metabolic disturbance associated with CRF is hyperlipidemia, closely related with decreased removal and increase of triacylglycerol production. Upregulation of fatty acid synthase (FAS) gene expression reveals another factor involved in disturbed lipid metabolism in CRF. It seems that elevated plasma insulin and cytokine concentration could play an important role in the mechanism responsible for the increased FAS gene expression in CRF [12].

Taking into account some of the ozone therapeutic properties, such as antiplatelet activity [13], enhancement of cell energy [14], and the increase of the antioxidant defense system $[15,16,17,18,19,20,21,22,23,24,25]$, the aim of this paper is to evaluate the effect of ozone therapy in the renal function, morphology, and biochemical parameters that measure oxidative stress in an experimental model of CRF.

\section{MATERIALS AND METHODS}

\section{Chemicals}

All reagents used in determinations of GSH, SOD, CAT, GSH-Px, and thiobarbituric acid reactive substances (TBARS) were purchased from Sigma Chemicals (St Louis, Mo). Other reagents of analytical grade were obtained from normal commercial sources.

\section{Animals}

Thirty young female Wistar rats (180-200 g) were maintained in an air-filtered and temperatureconditioned room (20-22C) with a relative humidity of $50 \%-52 \%$. Rats were fed with standard laboratory chow and water ad libitum and were kept under an artificial light/dark cycle of 12 hours. The experiments were performed in accordance with the ethical guidelines for investigations in laboratory animals and were approved by the Ethical Committee for Animal Experimentation of the National Center for Scientific Research, Havana, Cuba.

\section{Treatment schedule and surgical procedure}

Ozone $\left(\mathrm{O}_{3}\right)$ was generated by OZOMED 01 equipment manufactured by the Ozone Research Center (Cuba). Ozone was obtained from medical-grade oxygen by means of a silent electric discharge, representing about $3 \%$ of the gas mixture (ozone/oxygen). The ozone concentration was measured by using a UV spectrophotometer at $254 \mathrm{~nm}$. The ozone dose is the product of the ozone concentration, expressed as $\mathrm{mg} / \mathrm{L}$, by the gas mixture volume (L). By knowing the body weight of the rat, the ozone dose is calculated as $0.5 \mathrm{mg} / \mathrm{kg}$.

Surgery was performed as previously described [26]. Ventral laparotomy was performed under aseptic conditions after anesthesia (sodium pentobarbital, $30 \mathrm{mg} / \mathrm{kg}$ intraperitoneal route). The right kidney was then removed, while two-thirds of the left kidney underwent acute infarction by ligation of two first-order branches of the main renal artery. Recovery from anesthesia and from the surgical procedure was complete within 24 hours.

Animals were allocated randomly to 3 experimental groups of 10 animals each: (1) Sham group (negative control group), where rats underwent a ventral laparotomy under anesthesia as described above; however, only handling of the renal pedicle without the removal of renal mass was performed; (2) positive control group, where rats were subjected to 5/6 renal ablation as described above; and (3) ozone group, where rats were handled as in group 2 but also received, after the damage, 15 sessions of the gas mixture, composed of oxygen $\left(\mathrm{O}_{2}\right)+\mathrm{O}_{3}$ $(2.5-2.6 \mathrm{~mL}$ at a concentration of $50 \mu \mathrm{g} / \mathrm{mL}$, representing a dose of $0.5 \mathrm{mg} / \mathrm{kg}$ weight), by rectal insufflation, once per day.

\section{Sample preparation}

A day before the subtotal nephrectomy, all animals were housed in metabolic cages for 24 hours, without food and water ad libitum. In all animals, the weight and the systolic arterial pressure (SAP) in the tail, as well as protein excretion were measured. All these procedures and measurements were repeated, after the partial nephrectomy, once a week, for 10 weeks, the time during which, the CRF continued its evolution. The time of the study was not prolonged for more than 10 weeks, avoiding the unpredictable death due to the final stage of the CRF. In the last day of evolution, plasmatic clearance of $\mathrm{p}$ aminohippurate $(\mathrm{PAH})$ and inulin, in order to know the renal plasma flow (RPF) and the glomerular filtration rate (GFR), respectively, were determined using the method of unique injection (no urine) and the multicompartimental analysis of the plasmatic concentration curves in 9 blood samples [27]. Also, the urine excretion index (urine 
volume/water ingested) and sodium and potassium excretions were determined in order to know tubular work. Creatinine in serum was determined in the final blood sample obtained by intracardiac puncture $(2 \mathrm{~mL}$ of blood were extracted). Thereafter the animals were euthanized by ether anesthesia. The kidneys were dissected and immediately frozen at $-20 \mathrm{C}$ until analysis could be completed.

\section{Biochemical assays}

$\mathrm{PAH}$ and inulin were determined in deproteinated plasma samples by cadmium sulfate, using for PAH a photocolorimetric technique, modified by Smith and Tinkelstein [28]. Inulin was measured by the direct method of resorcinol without alkaline treatment [29]; corresponding calibration curves were used [30]. Proteins were calculated by the Biuret photocolorimetric technique using a Shimadzu spectrophotometer [31]. Potassium and sodium urine concentrations were measured for the calculation of the excretions of both substances in a Corning flame photometer (model 400), using the method described by Oser [32]. Creatinine in plasma was measured in deproteinated filtrates by the method of sodium tungstate, using for its evaluation the method of picric acid modified by Brot [33].

Kidney homogenates were obtained using a tissue homogenator Ultra-Turrax T25 polytron at 4C. The homogenates were prepared by using a $100 \mathrm{mM} \mathrm{KCl}$ buffer $(\mathrm{pH} 7)$ containing EDTA $0.3 \mathrm{mM}(1: 10 \mathrm{w} / \mathrm{v})$ for $\mathrm{GSH}$, TBARS, GSH-Px, and SOD determinations (buffer 1). The homogenates were spun down with a centrifuge at $600 \mathrm{~g}$ for 60 minutes at $4 \mathrm{C}$. The supernatants were taken for the biochemical determinations. GSH was determined by a slightly modified version of Beutler method [34], using a spectrophotometer. One $\mathrm{mL}$ of the kidney homogenate, as described before, was mixed with $1.5 \mathrm{~mL}$ of $5 \%$ metaphosphoric acid and centrifuged at $3000 \mathrm{~g}$ for 10 minutes at room temperature. Fifty hundred microliters of this acidic supernatant was mixed with $2 \mathrm{~mL}$ of $0.2 \mathrm{M}$ phosphate buffer and $0.25 \mathrm{~mL}$ of $0.04 \%$ 5,5'-dithio-bis-2-nitrobenzoic acid. Absorbance of the yellow solution was measured at $412 \mathrm{~nm}$ within 10 minutes. A molar extinction coefficient of $13.6 \mathrm{M} \mathrm{cm}^{-1}$ that describes the formation of the thiolate anion by the reaction of sulfhydryl groups with $5,5^{\prime}$-dithio-bis-2nitrobenzoic acid (DTNB) at $412 \mathrm{~nm}$ was used to quantify GSH.

Enzymatic activity of SOD was determined by a modified version of Minami and Yoshikawa method [35]. One unit of SOD enzymatic activity is equal to the amount of enzyme that diminishes the initial absorbance of nitro blue tetrazolium by $50 \%$.

CAT was determined according to Evans and Diplock method [36]. Kidney homogenates for CAT enzymatic assay were carried out using $50 \mathrm{mM}$ phosphate buffer $(\mathrm{pH} 7)$ containing 1\% Triton X-100 (1:9w/v) (buffer 2 ). The enzyme activity is expressed as the first-order constant that describes the decomposition of $\mathrm{H}_{2} \mathrm{O}_{2}$ at room temperature.

Enzymatic activity of GSH-Px was measured using a modified version of Thonson et al method (see [37]). The enzyme activity is expressed as international units of enzymatic activity/mg of protein. International units are expressed as $\mu \mathrm{mol}$ of hydroperoxides transformed $/ \mathrm{min} / \mathrm{mL}$ of enzyme.

To estimate TBARS levels, a method described by Ohkawa et al. [38] was used. The absorbance of $3 \mathrm{~mL}$ of the colored layer was measured spectrophotometrically at $532 \mathrm{~nm}$, using 1,1,3,3-tetraethoxypropane as a standard.

Protein concentrations were determined by the method of Lowry [39], using bovine serum albumin as a standard.

\section{Histological study}

Samples of rat kidneys were taken, fixed in 10\% neutral buffered formalin, processed, and embedded in paraffin. A pathologist unaware of the treatment schedule examined the histological sections, stained with hematoxylin and eosin.

\section{Statistical analysis}

First, the outliers preliminary tests for detection of error values were used. Afterward, the one-way analysis of variance (ANOVA) then homogeneity variance test (Bartlett-Box) were applied. In addition, Duncan's multiple range test and the Student $t$ test, for the comparison of two groups, were done. Results are presented as mean \pm standard deviation (SD). Different letters indicate a statistical significance of at least $P<.05$.

\section{RESULTS}

At the end of the study (10 weeks after the partial nephrectomy), animals treated with ozone showed SAP figures lower than those in the positive control group, but higher values compared to those in Sham group (negative control group). Urine excretion index, in the ozone group, was similar to the negative control group; however, positive control group showed lower values compared to those in the other groups (Table 1). Compared to protein excretion and serum creatinine, figures, in the ozone group, were higher than those in the negative control group, but lower than those in the positive control group. Potassium and sodium excretion values in negative control and ozone groups were similar, but lower in the positive group compared to negative and ozone groups (Table 1). RPF and GFR in ozone and Sham groups showed similar figures, but they are higher compared to those in positive control group (Table 1).

Histological renal injuries (RI) were $0 \%, 13 \%$, and $100 \%$ in the Sham, ozone, and positive control groups, respectively (Table 2). The histological findings for ozone and positive control groups were glomerular collapse (GC), tubule degeneration (TD), and cortical-medullary 
TABLE 1. Behavior of the systolic arterial pressure (SAP); urine excretion index; protein, potassium, and sodium excretions; creatinine figures; renal plasmatic flow (RPF); and glomerular filtration rate (GFR), at the end of the study, in the different groups. Data are mean $\pm \mathrm{SD} .{ }^{\mathrm{a}}{ }^{\mathrm{b}}{ }^{\mathrm{b}}$, and ${ }^{\mathrm{c}}$ denote statistical significance of at least $P<.05$.

\begin{tabular}{|c|c|c|c|}
\hline \multirow{2}{*}{ Measurements } & \multicolumn{3}{|c|}{ Groups } \\
\hline & Sham & Positive control & Ozone \\
\hline $\mathrm{SAP}(\mathrm{mmHg})$ & $111 \pm 13^{\mathrm{a}}$ & $165 \pm 13^{b}$ & $130 \pm 13^{b}$ \\
\hline Urine excretion index & $1.26 \pm 0.20^{\mathrm{a}}$ & $0.82 \pm 0.14^{\mathrm{b}}$ & $1.20 \pm 0.22^{\mathrm{a}}$ \\
\hline Protein excretion $(\mathrm{mg} / 24 \mathrm{~h} / 100 \mathrm{~g}$ rat $)$ & $1.31 \pm 0.23^{\mathrm{a}}$ & $8.78 \pm 2.06^{\mathrm{b}}$ & $4.08 \pm 0.85^{\mathrm{c}}$ \\
\hline Potassium excretion $(\mathrm{mEq} / 24 \mathrm{~h} / 100 \mathrm{~g}$ rat $)$ & $34.3 \pm 10.5^{\mathrm{a}}$ & $26.2 \pm 8.3^{\mathrm{b}}$ & $30.6 \pm 9.3^{\mathrm{a}}$ \\
\hline Sodium excretion $(\mathrm{mEq} / 24 \mathrm{~h} / 100 \mathrm{~g}$ rat $)$ & $575 \pm 55^{\mathrm{a}}$ & $440 \pm 60^{\mathrm{b}}$ & $507 \pm 40^{\mathrm{a}}$ \\
\hline Plasma creatinine $(\mu \mathrm{mol} / \mathrm{L})$ & $95 \pm 15^{\mathrm{a}}$ & $160 \pm 11^{\mathrm{b}}$ & $106 \pm 10^{c}$ \\
\hline $\mathrm{RPF}(\mathrm{mL} / \mathrm{min} / 100 \mathrm{~g}$ rat $)$ & $1.71 \pm 0.25^{\mathrm{a}}$ & $1.22 \pm 0.67^{\mathrm{b}}$ & $1.85 \pm 0.22^{\mathrm{a}}$ \\
\hline GFR (mL/min/100 g rat) & $0.34 \pm 0.01^{\mathrm{a}}$ & $0.26 \pm 0.06^{\mathrm{b}}$ & $0.36 \pm 0.02^{\mathrm{a}}$ \\
\hline
\end{tabular}

Table 2. Histological findings in the residual renal mass, due to the partial nephrectomy, in the different experimental groups, where GCD stands for glomerular capsule dilatation; GC glomerular collapse; CTD convoluted tubules dilatation; TD tubule degeneration; $\mathrm{CMH}$ cortical-medullar hemorrhages; and RI renal injury. * denotes statistical significance of at least $P<.05$

\begin{tabular}{lcccccc}
\hline Groups & GCD $\%$ & GC\% & CTD $\%$ & TD $\%$ & CMH\% & RI\% \\
\hline Sham & 0 & 0 & 0 & 0 & 0 & 0 \\
Positive control & 100 & 100 & 100 & 100 & 100 & 100 \\
Ozone & 100 & $20 *$ & 100 & $10^{*}$ & $10^{*}$ & $13^{*}$ \\
\hline
\end{tabular}

hemorrhages $(\mathrm{CMH})$, with $100 \%$ for the positive control group compared with $20 \%, 10 \%$, and $10 \%$, respectively, for the ozone group. Convoluted tubules dilatation (CTD) and glomerular capsule dilatation (GCD) were similar for these groups, shown in 100\% of animals. The histological study of renal cortex is observed in Figure 1. GCD and CTD are reversible structural alterations that appear in the first stages of the renal damage by vascular ablation. However, GC, TD, and $\mathrm{CMH}$ are lesions that have a significant effect in the glomerular-tubular relation, causing an irreversible damage in the renal function.

Subtotal nephrectomy induced a significant increase in TBARS $(P=.0253)$ of $144 \%$, whereas applications of ozone/oxygen gaseous mixture after subtotal nephrectomy increased TBARS to $90 \%(P=.0253)$ over the levels of positive control group (Table 3 ). SOD activity was significantly decreased to $55 \%(P=.0143)$ in positive control group, but, in ozone group, $39 \%$ of the enzymatic activity was recovered $(P=.0253)$. Ozone therapy after subtotal nephrectomy induced a total increase in SOD activity of $94 \%(P=.0281)$. A similar behavior was observed for CAT enzymatic activity. In positive control group there was a significant decrease of $50 \%$, whereas in ozone group a recovery of $218 \%$ was observed $(P=.0143)$ in the enzymatic activity of CAT, indicating a total increase in CAT activity of $268 \%(P=.0034)$. GSH concentration and GSH-Px enzymatic activity were not significantly affected by subtotal nephrectomy in this animal model, but when fifteen intrarectal applications of ozone/oxygen gaseous mixture were applied we observed a significant stimulation of GSH-Px, as well as an increase in GSH concentration. Renal GSH concentration was significantly increased to $87 \%(P=.0253)$ whereas GSH-Px activity was increased to $39 \%(P=.0253)$ (Table 3$)$.

\section{DISCUSSION}

Animals submitted to the subtraction of $5 / 6$ of the total renal mass moved forward the installation of the CRF, demonstrated by the decrease of RPF and GFR and the increase of SAP, plasma creatinine, protein excretion, decrease of potassium and sodium excretions, as well as the presence of renal damage in the histological study. This behavior is still more pronounced in the positive control group, where the renal damage reached $100 \%$.

The results have shown, at the end of the study, that the animals treated with ozone had the highest figures of RPF and GFR, as well as lower figures of proteinuria, plasma creatinine concentration, higher urine excretion, and lower SAP in comparison with the positive control group. These results can be linked to the ozone antiplatelet activity [10], diminishing blood viscosity, that could produce a decrease in the friction between the blood and the glomerular vascular walls, decreasing the flow resistance, increasing the RPF and GFR, achieving similar figures to those shown in the Sham group. The flow rise contributes to diminishing the endothelial injuries and the glomerular collapse, avoiding the tubular hypoxia, the hemorrhages, and the release of several proinflammatory cytokines [40, 41, 42, 43].

A depression in SOD expression was reported previously [11] for the same CRF model that we used, that could be correlated with the observed diminution in the activity of SOD and CAT, which can contribute to 


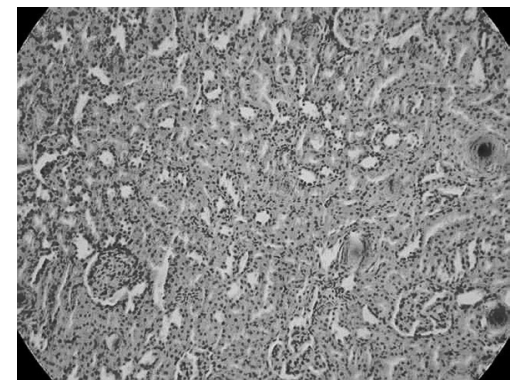

(a)

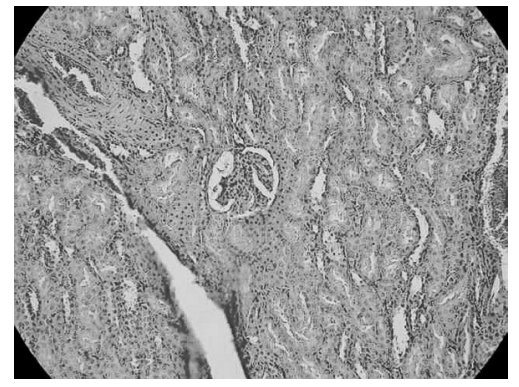

(b)

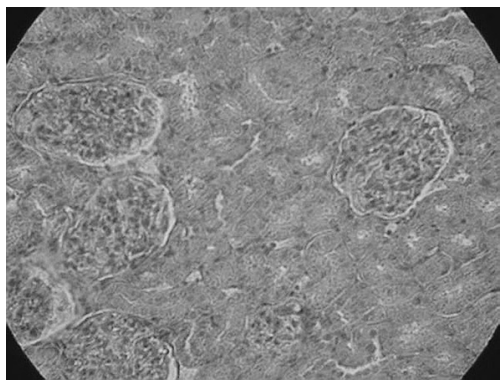

(c)

Figure 1. Histological study of the renal cortex. (a) Sham group (200×), normal morphology; (b) positive control group (200×), glomerular collapse, cortical hemorrhages, vascular congestion, dilatation of convoluted tubules and glomerular capsule dilatation; and (c) ozone group $(400 \times)$, a discrete dilatation of convoluted tubules.

TABLE 3. Renal concentration of different biochemical parameters, thiobarbituric acid reactive substances (TBARS), catalase (CAT), superoxide dismutase (SOD), reduced glutathione (GSH), and glutathione peroxidase (GPx), at the end of the study in the experimental groups. One unit of SOD enzymatic activity is equal to the amount of enzyme that diminishes the initial absorbance of nitroblue tetrazolium by $50 \%$ and CAT activity is described as the enzymatic activity quantity that transforms 1 mol of $\mathrm{H}_{2} \mathrm{O}_{2}$, at room temperature, at $15 \mathrm{~min} / \mathrm{g}$ of wet tissue. International units are expressed as $\mu \mathrm{mol}$ of transformed hydroperoxides $/ \mathrm{min} / \mathrm{mL}$ of $\mathrm{GPx} .{ }^{\mathrm{a}}$, ${ }^{\mathrm{b}}$, and ${ }^{\mathrm{c}}$ denote statistical significance of at least $P<.05$.

\begin{tabular}{lcrr}
\hline Biochemical parameters & \multicolumn{1}{c}{ Groups } & \multicolumn{1}{c}{ Ozone } \\
\hline TBARS (nmol/mg protein) & Sham & Positive control & $1.16 \pm 0.32^{\mathrm{c}}$ \\
CAT (K $15 /$ g of wet tissue) & $0.25 \pm 0.03^{\mathrm{a}}$ & $0.61 \pm 0.25^{\mathrm{b}}$ & $11.12 \pm 2.47^{\mathrm{c}}$ \\
SOD (units/mg protein) & $6.80 \pm 0.39^{\mathrm{a}}$ & $3.40 \pm 0.41^{\mathrm{b}}$ & $16.60 \pm 0.29^{\mathrm{c}}$ \\
GSH (nmol/mg protein) & $8.72 \pm 1.15^{\mathrm{a}}$ & $4.74 \pm 0.22^{\mathrm{b}}$ & $14.29 \pm 1.20^{\mathrm{b}}$ \\
GPX (IU/mg protein) & $7.87 \pm 0.90^{\mathrm{a}}$ & $7.84 \pm 0.47^{\mathrm{a}}$ & $10.47 \pm 1.22^{\mathrm{b}}$ \\
\hline
\end{tabular}

oxidative stress by increasing superoxide anion and hydrogen peroxide generation.

As it was reported before $[14,15,16,17,18,19,20,21$, $22,23,24]$, ozone therapy is an oxidative approach that by provoking brief moments of oxidative stress, may stimulate antioxidant system to fight against the phenomenon per se. Thus, the significant increase in lipid peroxidation, measured in the form of TBARS, was expected after the surgical procedure, followed by fifteen ozone applications. In spite of the significant increase in TBARS, an increase in antioxidant status was seen in the ozone group. The increase in renal TBARS might not be related with an increase in renal damage because the remarkable increase in antioxidant system surpasses this effect, inducing a general status of antioxidant protection.

Renal damage in this model of CRF might correspond with generation of ROS, such as superoxide anion and hydrogen peroxide. Renal GSH concentration and GSH-Px activity might not be directly affected by subtotal nephrectomy in this model. However, ozone therapy induced a significant increase in renal GSH amount and GSH-Px activity $(P=.0253)$, besides a remarkable stimulation of SOD and CAT activities, that surpass the increase in lipid peroxidation. This suggests that ozone therapy has a protective effect on renal tissue, by upregulation of the antioxidant system, protecting against the oxidative stress provoked by ischemia.

On the other hand, it had been demonstrated that ozone is able to regulate the calcium levels, maintaining its homeostasis, avoiding any damage to the cell structure [44]. Also, it is possible that the ozone therapy effect, with the stimulation of the antioxidant defense system $[14,15,16,17,18,19,20,21,22,23,24,25]$, protected the tissues against the oxidative stress shown in CRF [6], being in correspondence with the positive histological results obtained, where the ozone group showed the lowest percent of glomerular collapse, tubule degeneration, and cortical-medullary hemorrhages compared with positive control group.

In conclusion, in this animal model of CRF, rectal administrations of ozone produced a delay in the advance of the disease, protecting the kidneys against the deleterious effects shown in the CRF. Consequently, whenever possible, ozone therapy may become an important therapy to improve the quality of life of patients suffering CRF. 


\section{REFERENCES}

[1] Fauci AS, Braunwald E, Isselbacher KJ, et al. Chronic renal failure. In: Braunwald E, Hauser SL, Fauci AS, Longo DL, Kasper DL, Jameson JL, eds. Harrison's Principles of Internal Medicine. New York, NY: McGraw-Hill; 1998:1513-1520.

[2] Lane PH. Long-term furosemide treatment in the normal rat: dissociation of glomerular hypertrophy and glomerulosclerosis. Am J Kidney Dis. 1999;33(6):1058-1063.

[3] Fine LG. Adaptation of renal tubule in uremia. Kidney Int. 1982;22(5):546-549.

[4] Slomowitz L. Tubuloglomerular feedback in chronic renal failure. Nephron. 1987;45(4):264-271.

[5] Sheldin DW, Gusbech G. The kidney physiology and physiopathology. In: Roven Press, ed. The Kidney Physiology and Physiopathology. New York, NY: Roven Press; 1985:1901-1905.

[6] Ichikawa I, Kiyama S, Yoshioka T. Renal antioxidant enzymes: their regulation and function. Kidney Int. 1994;45(1):1-9.

[7] Yoshioka T, Ichikawa I. Glomerular dysfunction induced by polymorphonuclear leukocyte-derived reactive oxygen species. Am J Physiol. 1989;257(pt 2):F53-F59.

[8] Yoshioka T, Moore-Jarret T, Ichikawa I, Yared A. Reactive oxygen species of extra-renal origin can induce massive functional proteinuria. Kidney Int. 1990;37:497-502.

[9] Kawamura T, Yoshioka T, Bills T, Fogo A, Ichikawa I. Glucocorticoid activates glomerular antioxidant enzymes and protects glomeruli from oxidant injuries. Kidney Int. 1991;40(2):291-301.

[10] Yoshioka T, Bills T, Moore-Jarrett T, Greene HL, Burr IM, Ichikawa I. Role of intrinsic antioxidant enzymes in renal oxidant injury. Kidney Int. 1990;38(2):282-288.

[11] Vaziri ND, Dicus M, Ho ND, Boroujerdi-Rad L, Sindhu RK. Oxidative stress and dysregulation of superoxide dismutase and NADPH oxidase in renal insufficiency. Kidney Int. 2003;63(1):179-185.

[12] Szolkiewicz M, Nieweglowski T, Korczynska J, et al. Upregulation of fatty acid synthase gene expression in experimental chronic renal failure. Metabolism. 2002;51(12):1605-1610.

[13] Matsuno K, Miura T, Shinriki N. The effect of ozone on platelet activation. In: Proceedings of the 13th Ozone World Congress. Vol 3. Scottsdale, Ariz: Internaional Ozone Association; 1997:178-184.

[14] Bocci V. Ozone as a bioregulator: pharmacology and toxicology of ozonetherapy today. J Biol Regul Homeost Agents. 1996;10(2-3):31-53.

[15] Barber E, Menéndez S, León OS, et al. Prevention of renal injury after induction of ozone tolerance in rats submitted to warm ischaemia. Mediators Inflamm. 1999;8(1):37-41.

[16] Hernández F, Menéndez S, Wong R. Decrease of blood cholesterol and stimulation of antioxidative response in cardiopathy patients treated with endovenous ozone therapy. Free Radic Biol Med. 1995;19(1):115-119.

[17] León OS, Menéndez S, Merino N, et al. Ozone oxidative preconditioning: a protection against cellular damage by free radicals. Mediators Inflamm. 1998;7(4):289-294.

[18] Peralta C, León OS, Xaus C, et al. Protective effect of ozone treatment on the injury associated with hepatic ischemia-reperfusion: antioxidant-prooxidant balance. Free Radic Res. 1999;31(3):191-196.

[19] Candelario-Jalil E, Mohammed-Al-Dalain S, León OS, Menéndez S, Pérez-Davidson G, Merino N. Oxidative preconditioning affords protection against carbon tetrachloride-induced glycogen depletion and oxidative stress in rats. J Appl Toxicol. 2001;21(4):297-301.

[20] Ajamieh H, Merino N, Candelario-Jalil E, et al. Similar protective effect of ischaemic and ozone oxidative preconditionings in liver ischaemia/reperfusion injury. Pharmacol Res. 2002;45(4):333-339.

[21] Al-Dalain SM, Martínez G, Candelario-Jalil E, et al. Ozone treatment reduces markers of oxidative and endothelial damage in an experimental diabetes model in rats. Pharmacol Res. 2001;44(5):391-396.

[22] Ajamieh HH, Menéndez S, Martínez-Sánchez G, et al. Effects of ozone oxidative preconditioning on nitric oxide generation and cellular redox balance in a rat model of hepatic ischaemia-reperfusion. Liver Int. 2004;24(1):55-62.

[23] Ajamieh $\mathrm{HH}$, Berlanga J, Merino N, et al. Role of protein synthesis in the protection conferred by ozone-oxidative-preconditioning in hepatic ischaemia/reperfusion. Transpl Int. 2005;18(5):604612.

[24] Al-Dalain SM, Martínez G, Menéndez S, et al. Therapeutic efficacy of ozone medical treatments in patients with diabetic foot. Eur J Pharmacol. In press.

[25] Zamora Z, Borrego A, López O, et al. Effects of ozone oxidative preconditioning on TNF- $\alpha$ release and antioxidant-prooxidant intracellular balance in mice during endotoxic shock. Mediators Inflamm. 2005;2005(1):16-22.

[26] Anderson S, Meyer TW, Rennke HG, Brenner BM. Control of glomerular hypertension limits glomerular injury in rats with reduced renal mass. J Clin Invest. 1985;76(2):612-619.

[27] Folin O. A system of blood analysis. J Biol Chem. 1949;38:81-85.

[28] Smith HW, Tinkelstein N. The renal clearance of substituted hipuric acid derivatives and other aromatic acids in $\operatorname{dog}$ and man. J Clin Invest. 1945;24:388-391.

[29] Schreiner GE. Determination of inulin by means of resorcinol. Proc Soc Exp Biol Med. 1950;74(1):117120. 
[30] Jamison RL, Maffly RH. The urinary concentrating mechanism. N Engl J Med.1976;295(19):1059-1067.

[31] Oser BL. Determination of sodium and potassium. In: Hawk's, ed. Physiological Chemistry. New York, NY: MacGraw-Hill; 1965:1140-1145.

[32] Oser BL. Biuret test for protein determination. In: Hawk's, ed. Physiological Chemistry. New York, NY: MacGraw-Hill; 1965:179-184.

[33] Brot J. The renal clearance endogenous creatinine in man. J Clin Invest. 1948;27:645-54.

[34] Beutler E, Duron O, Mikus B. Improved method for the determination of blood glutathione. J Lab Clin Med. 1963;16:882-888.

[35] Minami M, Yoshikawa H. A simplified assay method of superoxide dismutase activity for clinical use. Clin Chim Acta. 1979;92(3):337-342.

[36] Evans C, Diplock AT. Techniques in free radical research. In: Burtin RH, Knippenberg PH, eds. Laboratory Techniques in Biochemistry and Molecular Biology. Amsterdam, The Netherlands: Elsevier; 1991:199-206.

[37] Faraji B, Kang HK, Valentine JL. Methods compared for determining glutathione peroxidase activity in blood. Clin Chem. 1987;33(4):539-543.

[38] Ohkawa H, Ohishi N, Yagi K. Assay for lipid peroxides in animal tissues by thiobarbituric acid reaction. Anal Biochem. 1979;95(2):351-358.

[39] Lowry OH, Rosebrough NJ, Farr AL, Randall RJ. Protein measurement with the Folin phenol reagent. J Biol Chem. 1951;193(1):265-275.

[40] Mezzano SA, Droguett M, Burgos ME, et al. Overexpression of chemokines, fibrogenic cytokines, and myofibroblasts in human membranous nephropathy. J Kidney Int. 2000;57(1):147-158.

[41] Hansch GM, Wagner C, Burger A, Dong W, Staehler G, Stoeck M. Matrix protein synthesis by glomerular mesangial cells in culture: effects of transforming growth factor beta (TGF beta) and platelet-derived growth factor (PDGF) on fibronectin and collagen type IV mRNA. J Cell Physiol. 1995;163(3):451-457.

[42] Ito Y, Aten J, Bende RJ, et al. Expression of connective tissue growth factor in human renal fibrosis. Kidney Int. 1998;53(4):853-861.

[43] Fine LG, Orphanides C, Norman JT. Progressive renal disease: the chronic hypoxia hypothesis. Kidney Int. 1998;53(suppl 65):S74-S77.

[44] León OS, Menéndez S, Merino N, et al. Influencia del precondicionamiento oxidativo con ozono sobre los niveles de calcio. Revista CENIC Ciencias Biológicas. 1998;29(3):134-136. 


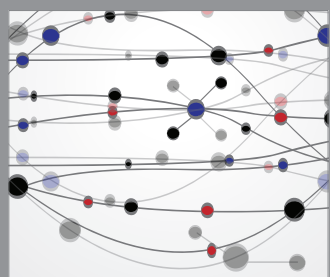

The Scientific World Journal
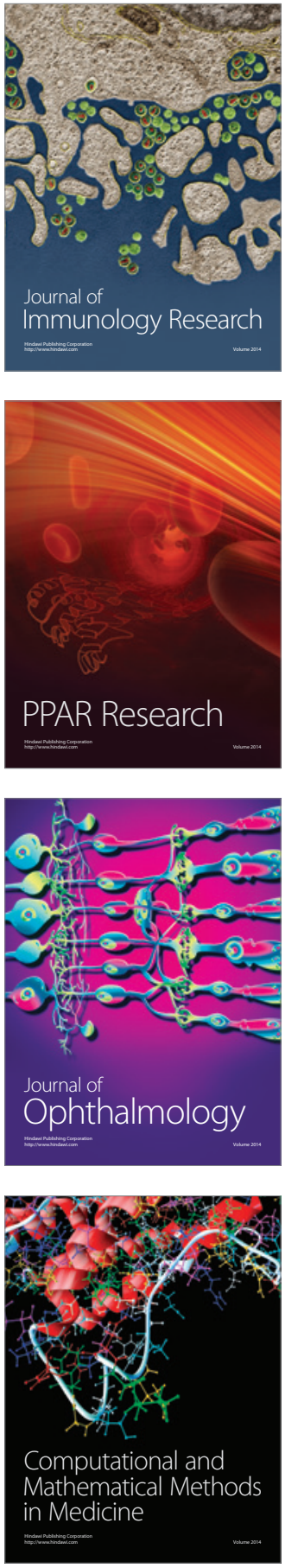

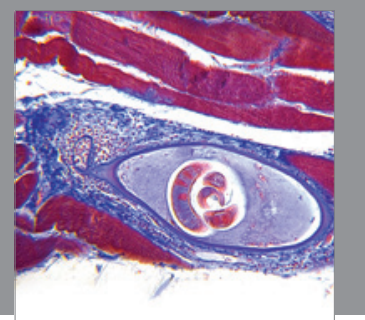

Gastroenterology

Research and Practice
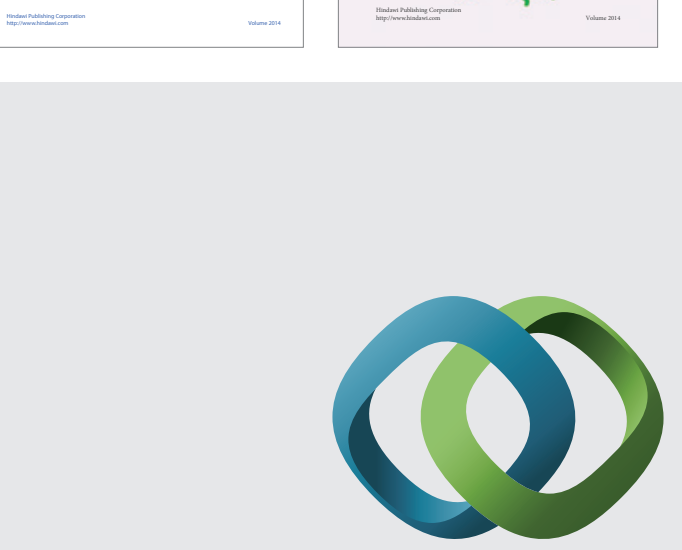

\section{Hindawi}

Submit your manuscripts at

http://www.hindawi.com
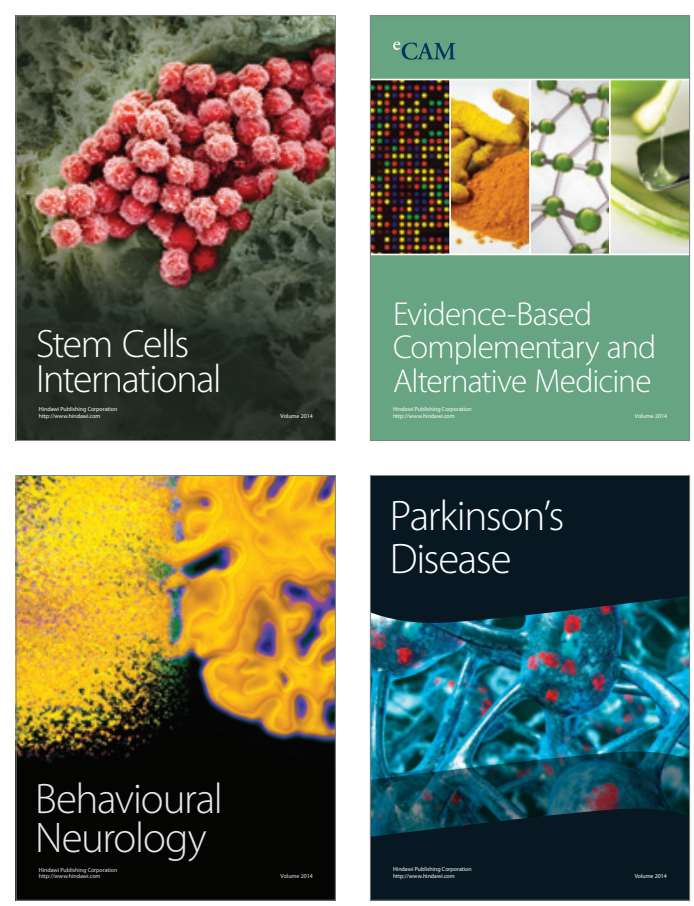

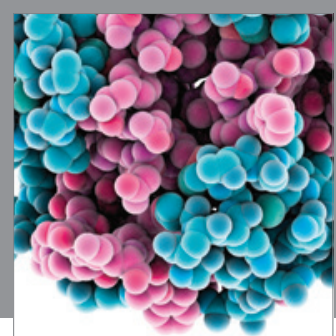

Journal of
Diabetes Research

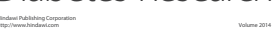

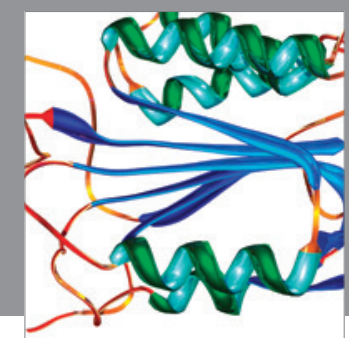

Disease Markers
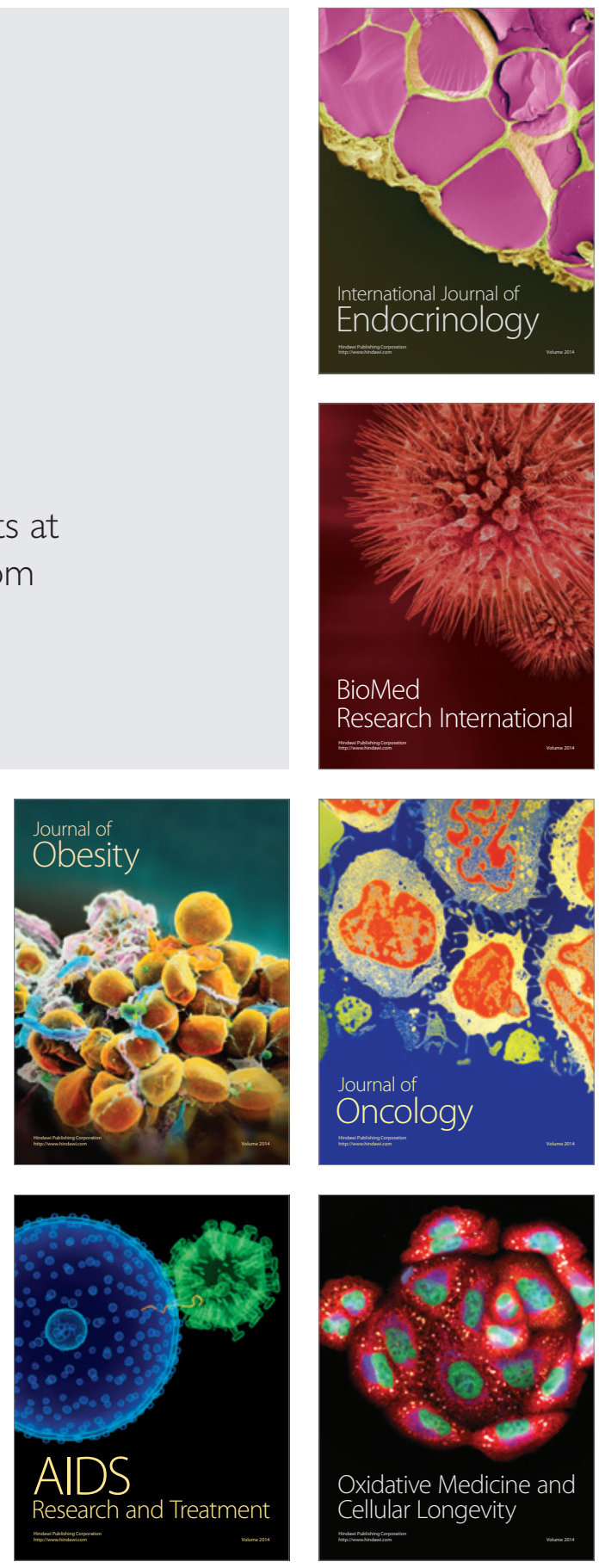